\title{
Risks and benefits of percutaneous vertebroplasty or kyphoplasty in the management of osteoporotic vertebral fractures
}

\author{
O. Lamy • B. Uebelhart • B. Aubry-Rozier
}

Received: 9 September 2013 / Accepted: 6 November 2013 / Published online: 22 November 2013

(C) International Osteoporosis Foundation and National Osteoporosis Foundation 2013

\begin{abstract}
Vertebral fracture (VF) is the most common osteoporotic fracture and is associated with high morbidity and mortality. Conservative treatment combining antalgic agents and rest is usually recommended for symptomatic VFs. The aim of this paper is to review the randomized controlled trials comparing the efficacy and safety of percutaneous vertebroplasty (VP) and percutaneous balloon kyphoplasty (KP) versus conservative treatment. VP and KP procedures are associated with an acceptable general safety. Although the case series investigating VP/KP have all shown an outstanding analgesic benefit, randomized controlled studies are rare and have yielded contradictory results. In several of these studies, a short-term analgesic benefit was observed, except in the prospective randomized sham-controlled studies. A long-term analgesic and functional benefit has rarely been noted. Several recent studies have shown that both VP and $\mathrm{KP}$ are associated with an increased risk of new VFs. These fractures are mostly VFs adjacent to the procedure, and they occur within a shorter time period than VFs in other locations. The main risk factors include the number of preexisting VFs, the number of VPs/KPs performed, age, decreased bone mineral density, and intradiscal cement leakage. It is therefore important to involve the patients to whom VP/KP is being proposed in the decision-making process. It is also essential to rapidly initiate a specific osteoporosis therapy when a VF occurs (ideally a bone anabolic treatment) so as to reduce the risk of fracture. Randomized controlled studies are
\end{abstract}

O. Lamy $(\bowtie) \cdot$ B. Aubry-Rozier

Center of Bone Diseases-Bone and Joint Department, Lausanne

University Hospital, Av Pierre-Decker, 4, 1011 Lausanne,

Switzerland

e-mail: olivier.lamy@chuv.ch

B. Uebelhart

Service of Bone Diseases, Geneva University Hospital, Geneva, Switzerland necessary in order to better define the profile of patients who likely benefit the most from VP/KP.

Keywords Kyphoplasty · Osteoporosis · Vertebral fracture · Vertebroplasty

\section{Introduction}

VF is the most common complication of osteoporosis. It is associated with increased morbidity and mortality and, in a minority of patients, with considerable pain. It is estimated that $3 \%$ of all VFs are pathological, $14 \%$ are trauma-related, and $83 \%$ are osteoporotic [1]. For women at the age of 50, the residual risk for VF is $32 \%$ [2]. In both the USA and Europe, annual risk increases with age, ranging from $0.4-0.6 \%$ in women who are between 50 and 54 to $1.2-1.3 \%$ in those who are between 65 and 69 , and to $2.9-3.8 \%$ in those who are 85 or older [3, 4].

$\mathrm{VF}$ is widely underdiagnosed in all countries. The IMPACT study showed this for North America, South America, Europe, Australia, and South Africa [5]. However, the underdiagnosis may be related to a problem of qualitative or quantitative definition of VF. Nearly $70 \%$ of VFs are not clinically recognized as such because they are asymptomatic or only slightly symptomatic, or they are not diagnosed $[6,7]$.

Symptomatic VFs cause as many days of confinement to bed and functional incapacity as hip fractures, if not more [8]. Quality of life can be very much lowered following symptomatic or asymptomatic VF [9-12]: height loss and kyphosis, besides physical pain, symptoms include sleeping disorders, fear of a fall that may lead to new fractures, loss of confidence, and psychological disorders ranging from anxiety to depression. When serious, thoracolumbar static disorders may cause a reduction in respiratory function (restrictive syndrome) as well as digestive disorders (early satiety) accompanied by loss 
of weight. The simple movements of daily life become more and more difficult. All these problems may lead to isolation, a situation that is much feared in geriatric medicine. Moreover, the VF increases the risk of mortality. The consequences of VF, especially the mortality, increase with the number and the severity of VF.

The presence of a VF increases the risk of new vertebral and non-vertebral fractures. In the Rochester study, the cumulated incidence of suffering a new fracture (or several fractures) during the year following the first VF was around $20 \%$; at 10 years, cumulated risk was more than $70 \%$ [13]. The presence of a VF increases the risk of new VFs from 3 to 12 and the risk of non-vertebral fractures from 1.5 to 4 [6, 13-17]. The more severe the VF is, and the more VFs there are, the more the risk of vertebral and non-vertebral fracture recurrence increases [18]. In the MORE study, over the 3 years, the risk of VF recurrence increased from $10.5 \%$ in the presence of a prior $\mathrm{VF}$ of grade I to $38.1 \%$ when the VF was grade III [19].

Many antiresorptive and anabolic therapies have shown efficacy in lowering the risk of VF recurrence in randomized trials against placebo. The percent of fracture reduction given below should not be compared. SERMs, oral bisphosphonates, and strontium ranelate have been reported to lower this risk by around $50 \%$; zoledronic acid, denosumab, and teriparatide by nearly $70 \%$. The antifracture effect is obtained after 6 to 12 months. These therapies are also particularly efficacious for reducing the risk of multiple VFs, and so may lower the ensuing pain and morbidity. Of the common osteoporosis therapies, teriparatide was the only one to have shown efficacy in reducing back pain compared with other osteoporosis therapies or placebo [20-22]. As the risk of subsequent fractures is very high during the first months that follow a VF, and as the therapies are rapidly efficacious, it is essential to initiate these therapies without delay. Patients receiving an osteoporosis therapy must have a sufficient intake of calcium (around 1,200 mg/day) and vitamin D (around $800-1,000 \mathrm{IU} /$ day or $20-25 \mu \mathrm{g} /$ day). This intake optimizes the effect of osteoporosis treatments and improves musculoskeletal health while lowering the risk of falls and fractures.

Treating a symptomatic VF often requires immobilization and antalgic agents. The role of contention on pain is controversial, partly because of a lack of data. Acute treatment only applies to symptomatic fractures. Nonsteroidal analgesics at reasonably high doses are the treatment of choice. Morphine derivatives may be included in case of failure, and calcitonin may be used for 4 weeks [23]. Both confinement to bed and the use of certain analgesics over long periods are associated with several side effects that are particularly worrying in the elderly, such as deconditioning, respiratory superinfection, impaired balance, and increased risk of falling. To avoid these side effects, or when pain cannot be controlled, minimally invasive treatment may be suggested. VP and KP are proposed to relieve VF-related pain; KP also enables vertebral height to be partially restored and secondary kyphosis to be limited.

\section{Method}

The authors conducted a MEDLINE search using relevant search terms including osteoporosis, osteoporotic vertebral compression fracture, kyphoplasty, and vertebroplasty. This article is a review of the randomized controlled studies that have been published comparing VP or KP with conservative treatment, or VP with KP following osteoporotic VF (Table 1). Because there are not many randomized studies on this subject, case series and retrospective and prospective cohort analyses were included whenever they provided pertinent additional information. In order to limit the length of this article, we based our research on literature reviews as well as on meta-analyses of good quality [24-26].

First, we summarized the historical and technical aspects of VP and KP. Second, the articles were analyzed in terms of benefits: pain relief, quality of life, functional improvement, and increase of vertebral height. Third, we analyzed the side effects and complications of VP and KP.

\section{Vertebroplasty and kyphoplasty: history and technical aspects}

The first VPs were performed in 1984 in order to treat symptomatic vertebral angiomas [27]. Their use was next extended to the treatment of symptomatic vertebral metastases, and then to traumatic VFs. It was at the beginning of the 1990s that the procedure was used in the analgesic treatment of osteoporotic VFs.

VP involves the injection of a radiopaque cement under Xray guidance, usually a polymethylmethacrylate resin (PMMA) [28]. The procedure is performed via the transpedicular approach (ideally bilaterally) through a trocar under local or general anesthesia. PMMA is a two-component (liquid/powder) resin. It is combined with a contrast agent so that the procedure can be followed. After between 8 and $10 \mathrm{~min}$, the PMMA polymerizes and hardens, a process which is accompanied by an exothermic reaction reaching up to around $75^{\circ} \mathrm{C}$ in the center of the vertebra. The analgesic effect of VP is attributed to several factors, including the thermal reaction, as well as the consolidation and stabilization of the fracture. VP requires that the resin be injected at relatively high pressure because of its low viscosity [29]. This is accompanied by a high risk of cement leakage. It is often said that VP must be performed fairly soon after a VF to obtain the analgesic effect. However, authors have shown analgesic benefits for VFs up to 1 year after their occurrence [30, 31]. Nieuwenhuijse et al. analyzed the relationship between the fracture date and VP efficacy in 115 patients who had undergone 216 VPs [31]. The mean time from fracture to VP was $6.0 \pm 2.9$ months. The authors concluded that the analgesic benefits and improvement in quality of life obtained were independent of the length of time between the VF and VP. 


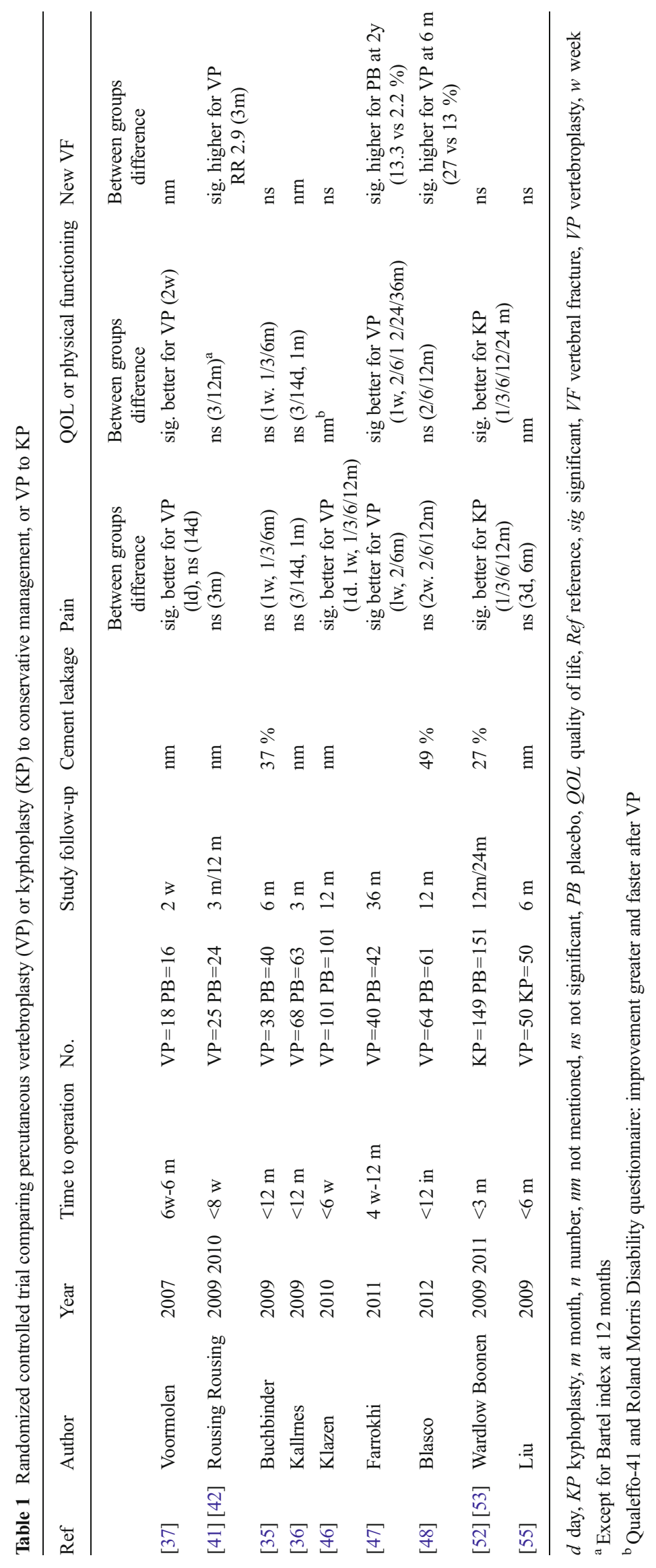


KP was developed to improve VP [32], using the same approach route as for VP. An inflatable balloon is inserted via the trocar, allowing a void to be made. The balloon is then removed, and the cement is injected at lower pressure into the void. The theoretical advantages are a lowering of the risk of cement leakage and (partial) restoration of anterior and middle vertebral wall height. KP was approved by the US Food and Drug Administration in 1998.

Before performing VP/KP, magnetic resonance imaging (MRI) must be conducted to verify that the posterior wall is intact. Table 2 summarizes the usual contraindications to VP/ KP [33]. VP takes less time than KP and costs less. These highly promising procedures were very popular between the years 2000 and 2009. They are mainly performed by radiologists, orthopedists, and neurosurgeons. In the USA, the number of VPs performed increased from around 14,000 in 2001 to nearly 30,000 in 2005 , and the number of KPs from around 43,000 in 2006 to more than 50,000 in 2008 [34]. Following the publication of reports that called into question the clinical benefit of VP in 2009, the number of VPs and KPs performed decreased by $10 \%$ [34-36].

\section{Vertebroplasty and kyphoplasty: efficacy}

\section{Efficacy of vertebroplasty}

The first publications that included case reports and case series all concluded that VP had an outstanding analgesic effect in around $90 \%$ of patients. In 2009, a large literature review of VP and KP for osteoporotic VFs was published [25]. The results of that review suggested that there were analgesic and functional benefits observed during the first 3 months following VP compared with conventional medical treatments. Of the 74 studies analyzed, 70 were case series. There was only one randomized controlled study comparing VP with medical

Table 2 Usual contraindications to percutaneous vertebroplasty or kyphoplasty

Osteoporotic vertebral fracture related contraindications

- Fracture with posterior wall defect

- Severe vertebral body collapse (vertebra plane)

- Prophylaxis with no evidence of acute fracture

- Asymptomatic stable fracture

Other vertebral diseases related contraindications

- Osteomyelitis or spondylodiscitis

- Tumor extension into epidural space

General contraindications

- Uncorrected coagulation disorders

- Allergy to any required component

- Pregnancy treatment [37], and there were three prospective nonrandomized controlled studies comparing the two treatment strategies [38-40]. The Vertos randomized controlled study included 34 patients, 18 in the VP group and 16 in the optimal medical therapy (OMT) group [37]. Analysis at day 1 and at week 2 showed an analgesic and functional benefit in the VP group. Due to the low number of patients and high rate of switching from the OMT group to the VP group, no conclusions could be drawn regarding potential long-term benefits. The three non-randomized controlled studies confirmed these rapid benefits for the patients who had undergone VP. Diamond et al. compared 55 patients treated by VP with 24 receiving OMT [38]. The analgesic and functional benefits observed at the beginning were no longer significant after 1.5, 6 , and 12 months. Alvarez et al. compared 101 patients treated by VP with 27 receiving OMT [39]. In the VP group, the analgesic benefit was significant at 3 and 6 months; the functional benefit was significant at 3 months. At 12 months, there was no longer any difference between the two groups. In a second trial, Diamond et al. prospectively followed up 88 patients treated by VP and 38 who received OMT [40]. The analgesic and functional benefits were significant in the VP group at 6 weeks, but there was no difference at 1 and 2 years. The other 70 case series all reported an immediate analgesic benefit [25]. Thus, there was a trend in the literature supporting a rapid analgesic and functional benefit with VP when performed for osteoporotic VF management. Also in 2009, but not included in the meta-analysis of McGirt et al., Rousing et al. published a randomized controlled study, which, however, exhibited methodological shortcomings regarding pain evaluation [41]. The VP group had an immediate analgesic benefit within 12 to $24 \mathrm{~h}$ of the procedure that was significantly greater than that of the control group. The authors reported two new VFs in the VP group, whereas there were none in the control group, after 3 months. Follow-up at 3 and 12 months showed no difference in terms of analgesic benefits between the two groups [41, 42].

There was controversy when two prospective randomized sham-controlled studies were published in the New England Journal of Medicine in 2009 [35, 36]. The patients in both the VP and control groups were managed under the same conditions: treatment in the interventional radiology room, local anesthesic infiltration of the posterior longitudinal ligament, and cement prepared beside the patients. A sham insertion of a trocar into the vertebra was performed in the control group; only the VP group was injected with cement. Buchlinder et al. enrolled 78 patients who had suffered one or two painful MRIconfirmed osteoporotic VFs within the previous 12 months with unfavorable clinical evolution [35]. The patients were stratified according to the duration of symptoms ( $<6$ weeks or $\geq 6$ weeks). They were evaluated at 1 week and at 1,3 , and 6 months. The primary outcome was overall pain on a scale of 0 to 10 . VP showed no benefit at any time compared with the 
control group in terms of pain, functional status, quality of life, or even perceived improvement. For example, at 3 months, the mean reduction in the pain score was $2.6 \pm 2.9$ in the VP group and $1.9 \pm 3.3$ in the control group (adjusted betweengroup difference, $0.6 ; 95 \% \mathrm{CI},-0.7$ to 1.8 ). Kallmes et al. enrolled 131 patients who had between one and three painful CT- or MRI-confirmed osteoporotic VFs for less than 12 months with unfavorable clinical evolution [36]. The primary outcomes were scores on the modified Roland-Morris Disability Questionnaire (RDQ) and overall pain on a scale of 0 to 10 at 1 month. There was an immediate improvement with regard to pain in both groups. At 1 month, there was no significant difference between the VP and control groups in either the RDQ score (difference $0.7 ; 95 \% \mathrm{CI},-1.3$ to 2.8 ; $P=0.49$ ) or the pain score (difference $0.7 ; 95 \% \mathrm{CI},-0.3$ to 1.7 ; $P=0.19$ ). At 3 months, there was a high rate of crossover (51\%) in the control group. It was therefore not possible to evaluate VP's benefit at 3 or 6 months. Despite the negative results of these two prospective randomized sham-controlled studies, several authors voiced objections, pointing out that VP should be reserved for patients with acute VF of recent onset ( $<6$ weeks), for those who have severe pain, or for those in whom MRI has shown edema to be present $[43,44]$. In response to some of these objections, a meta-analysis of these two studies was conducted using the individual data of the 209 patients [45]. The analyses took into account the date of the VF ( $\leq$ or $>6$ weeks) and severity of pain on a scale of $10(\geq$ or $<8)$. For the patients with recent pain ( $\leq 6$ weeks), between-group differences at 1 month for pain and disability scores were $0.1(95 \% \mathrm{CI},-1.4$ to 1.6 ) and 0.2 (95\% CI, -3.0 to 3.4), respectively. For patients with severe pain $(\geq 8)$, between-group differences at 1 month for pain and disability scores were $0.3(95 \% \mathrm{CI},-0.8$ to 1.5$)$ and 1.4 ( $95 \% \mathrm{CI},-1.2$ to 3.9 ), respectively. At the beginning of the study, $68 \%$ of patients in the different groups were on opioids. Surprisingly, at 1 month, there were more VP patients than control patients on opioids (64 versus $46 \% ; P=0.018$ ). The authors of this meta-analysis concluded that VP did not offer any benefit, not even in the subgroups of patients who theoretically should have benefited the most.

VERTOS II, an open-label randomized trial, was published in 2010 [46]. The authors enrolled 202 patients who had a VF and met strict criteria: pain for less than 6 weeks, a visual analogue scale (VAS) score $\geq 5$, and edema on MRI. The patients who were randomized into the VP group had better pain control at 1 month and 1 year than the control group. The difference between the groups in the reduction of mean VAS score from baseline was $2.6(95 \% \mathrm{CI}, 1.7-3.4 ; P<0.0001)$ at 1 month and $2.0(95 \% \mathrm{CI}, 1.1-2.8, P<0.0001)$ at 1 year. One randomized controlled study involving 82 patients (refractory to analgesic therapy for $>4$ weeks and $<1$ year) showed a highly significant improvement in pain relief for 6 months and quality of life for at least 36 months [47]. All patients in the OMT group were treated with analgesic agents, calcitonin and alendronate. After 2 years of follow-up, the incidence of new VFs in the OMT group was higher than in the VP group (13.3 versus $2.2 \% ; P<0.01)$. The VP was made via a unilateral parapedicular approach in $87.5 \%$ of patients. The cement leakage was only $14 \%$ (including intervertebral disc, epidural and paravertebral space). Ten patients in the OMT group with persistent pain and low level of quality of life 1 year after the study started crossed over to VP. They had a significant pain relief. An open-label randomized trial published in 2012 enrolled 125 patients [48]. There was a significant decrease in VAS in both groups. However, at 2 months, VAS improvement was greater in the VP group than in the control group (mean differences $1.59 \pm 0.42$ versus $3.07 \pm 0.45, P=0.017$ ). The quality of life questionnaire of the European Foundation for Osteoporosis (Qualeffo-41) was significantly improved in the VP group at the evaluation time points, whereas the improvement in the control group was significant only after 6 months. There were no differences between the two groups at 1 year, be it for VAS or Qualeffo-41. However, there were significantly more new VFs in the VP group (OR 2.78; $95 \%$ CI, 1.02-7.62, $P=0.046$ ).

\section{Efficacy of kyphoplasty}

An initial meta-analysis published in 2006, which was mainly based on case series, included 26 studies involving 1,490 patients who had undergone 2,643 KPs [49]. The analysis results documented a mean VAS reduction of -5.1 , an augmentation of anterior vertebral wall height of $13.4 \%$, a reduction in kyphosis as measured by Cobb's angle of $-7.7 \%$, and an improvement in functional indices of $+20 \%$. However, the authors emphasized the methodological shortcomings of these studies and the insufficient follow-up of patients. By 2009, 35 studies pertaining to KP had been published [25]. Thirty-three studies were case series, and all concluded that there was a rapid analgesic effect. There was no randomized controlled study, and only one prospective non-randomized controlled study, which was published in two parts [50, 51]. Forty patients treated by KP were compared with 20 patients receiving conventional medical treatment. There was an analgesic benefit and functional improvement at 3, 6, and 12 months in the KP group. The Fracture Reduction Evaluation Study (FREE) has been the only randomized controlled study to have compared KP with conventional medical treatment [52]. A total of 300 patients were randomized after a mean 6-week period following a VF (osteoporosis-related in $95 \%$ of cases). The primary outcome was the difference in change from baseline to 1 month in the short-form SF-36 physical component summary (PCS) score (scale 0-100). Mean SF-36 PCS score improved by 7.2 points ( $95 \%$ CI, 5.7-8.8), from 26.0 at baseline to 33.4 at 1 month, in the KP group, and by 2.0 points $(95 \% \mathrm{CI}, 0.4-3.6)$, from 25.5 to 27.4 , in the control group (difference between groups 5.2 points, 2.9-7.4; $P<$ 
0.0001). This benefit for the KP group was still present at 1 year. The same applied to five other scores concerning pain and/or functional capacity. The beneficial effect was significantly better for the KP group at each time point (1, 3, 6, and 12 months). Analgesic benefit and some functional benefits were still higher in the KP group compared with the control group after 24 months of follow-up [53]. There was no significant difference in the occurrence of new radiological VFs after 24 months of follow-up: $47.5 \%$ in the KP group versus $44.1 \%$ in the control group. Around $80 \%$ of VFs occurred during the first year. A prospective study comparing KP with conservative treatment during the first 3 weeks following a symptomatic VF showed that KP had an analgesic benefit only during the first month after the procedure [54]. The authors concluded that patients should be treated conservatively before KP is considered.

\section{Vertebroplasty versus kyphoplasty}

There has been only one randomized controlled study comparing VP with KP for osteoporotic VFs. Liu et al. enrolled 100 patients presenting with a VF that had occurred less than 6 months before [55]. The time period between the VF and the procedure was 17.0 days for KP and 15.8 days for VP. There was an excellent analgesic effect in both groups, with no significant difference. A reduction in the kyphosis angle was observed in both groups, but it was significantly greater in the $\mathrm{KP}$ group $(P<0.001)$. More PMMA was used in the KP group than in the VP group $(5.56 \pm 0.62$ versus $4.91 \pm 0.65 \mathrm{~mL}, P<$ 0.001). Follow-up lasted 6 months, and there were two new VFs, both of which occurred in the KP group. There have been nine case series comparing VP with KP, with between 45 and 154 patients enrolled in each [56-64]. The groups were highly heterogeneous, making it very difficult to compare the results. Mean age ranged from 62 to 78, and the duration of follow-up varied between 6 and 42 months. When it was mentioned, the volume of PMMA injected ranged from 2.5 to $5.8 \mathrm{~mL}$ in the VP groups and from 1.8 to $5.6 \mathrm{~mL}$ in the $\mathrm{KP}$ group. An excellent meta-analysis comparing VP with KP has recently been published [26]. In the 10 studies analyzed, which encompassed 783 patients, there was no difference between the VP and KP groups in terms of short- and longterm analgesic effects or short- and long-term functional benefits. Operation time was the same for both procedures. But KP was superior to VP with regard to the following points: long-term improvement of kyphosis angle (mean difference $=$ $-2.64,95 \% \mathrm{CI},-4.66$ to $-0.61 ; P=0.01)$, improvement in anterior height of vertebral body (mean difference $=3.67 \mathrm{~mm}$, $95 \% \mathrm{CI}, 1.40$ to $5.94 ; P=0.002$ ), and reduction in cement leakage ( $\mathrm{RR}=0.70,95 \% \mathrm{CI}, 0.52$ to $0.95 ; P=0.02$ ). The risk of a VF adjacent to the treated vertebra was 7.1 and $3.7 \%$ for the KP and VP groups, respectively, with no significant difference noted. It is not certain that a difference of $2^{\circ}$ to $3^{\circ}$ on the kyphosis angle or an increase of 3 to $4 \mathrm{~mm}$ of the anterior height of vertebral body will have a clinical relevance. To answer this question, it is necessary to have a randomized study with the kyphosis angle as primary endpoint.

\section{Side effects and complications of vertebroplasty and kyphoplasty}

Main side effects

Complications are more common when VP/KP is performed for metastatic VFs than when it is performed for osteoporotic VFs. It is necessary to distinguish between asymptomatic side effects, symptomatic side effects, and long-term complications. Asymptomatic side effects are associated with cement leakage along the trocar route, in the epidural and intradiscal regions, or with intravenous cement leakage. Cement leakage is much less frequent with KP than VP [33, 65-68]. It may concern up to $70 \%$ of patients depending on the series and study methods, but is most often neglected [69]. However, some asymptomatic side effects are a cause of worry. In VERTOS II, pulmonary embolisms were screened by chest CT and found in $26 \%(95 \% \mathrm{CI}, 16-39 \%)$ of patients [70]. All the patients were asymptomatic. Cement leakage into the azygos vein was the only risk factor identified for pulmonary embolism (OR 43; 95 \% CI, 5-396). The short-term symptomatic side effects of VP/KP for osteoporotic VFs usually concern between 1 and $3 \%$ of patients, and seem to be even less in more recent series. In Hulme's review, the risk of complications was $3.9 \%$ after VP and $2.2 \%$ after KP [65]. Leakage into the epidural space, spinal canal, or foramen may cause medullary or spinal damage. Venous leakage may, in rare cases, result in symptomatic pulmonary embolism. Infections and hematomas are very rare. Table 3 provides the main side effects of these procedures, as well as their rate of occurrence. In an Italian series involving 4,547 patients who had undergone at least one VP (of whom $73 \%$ for osteoporosis), the side effects observed were as follows: venous cement leakage 930 (20.5\%), intradiscal cement leakage 490 (10.8\%), symptomatic pulmonary embolism 45 (1.0\%), cement leakage into spinal canal $5(0.1 \%)$, hematoma 2 $(0.04 \%)$, and infection $2(0.04 \%)$ [71]. For all these, side effects should be taken into account the date of publication. Indeed, the quality of biomaterials improves and operators experience increases. This is particularly true for cement leakage, less frequently described in recent studies

Risk of new vertebral fracture

This risk was not analyzed in the first studies of VP/KP, since osteoporotic vertebral fragility was in itself a strong risk factor for refracture (Tables 3 and 4). What is more, in the studies, 
Table 3 Side effects and complications of percutaneous vertebroplasty or kyphoplasty

$K P$ kyphoplasty, $V F$ vertebral fracture, $V P$ vertebroplasty

\begin{tabular}{llll}
\hline & & Technique & References \\
\hline Asymptomatic side effects & & & \\
Intervertebral disc cement leakage & $10-27 \%$ & $\mathrm{KP}$ & {$[51,52,68]$} \\
Intervertebral disc cement leakage & $10-75 \%$ & $\mathrm{VP}$ & {$[51,68,76]$} \\
Paravertebral veins cement leakage & $20 \%$ & $\mathrm{VP}$ & {$[71]$} \\
Asymptomatic pulmonary embolism & $26 \%$ & $\mathrm{VP}$ & {$[70]$} \\
Symptomatic side effects & $1-3 \%$ & $\mathrm{VP} / \mathrm{KP}$ & {$[68,71]$} \\
Neurological complications & $>1 \%$ & & {$[36,68,71]$} \\
Infection & $>1 \%$ & & {$[35,67,71]$} \\
Symptomatic pulmonary embolism & $\leq 1 \%$ & & {$[71]$} \\
Hematoma & $<1 \%$ & & {$[52,71]$} \\
Risk of secondary VF & & & {$[48,68,74,75,77]$} \\
Clinical VF at 12 months & $13-27 \%$ & $\mathrm{VP} / \mathrm{KP}$ & {$[69,78]$} \\
Clinical VF at 24 months & $21-27 \%$ & $\mathrm{VP}$ & {$[53,79]$} \\
Radiological VF at 12 months & $30-38 \%$ & VP/KP & {$[40,53]$} \\
Radiological VF at 24 months & $44-48 \%$ & KP & \\
\hline
\end{tabular}

the radiological and clinical VFs have to be distinguished. There does indeed seem to be an increased risk of subsequent $\mathrm{VF}$, in particular to the vertebrae adjacent to the percutaneous procedure. Already in 2003, a series involving 177 patients who had undergone VP reported the occurrence of 36 VFs in $22(12.4 \%)$ of them [72]. Of these 36 VFs, 24 (67\%) occurred in vertebral levels adjacent to the VP, and two thirds of the VFs occurred in the first 30 days after the VP. A small series published in 2004 showed an increased risk of adjacent VFs in the first 2 months following KP [73]. In 2006, two new studies described an increased risk of VF adjacent to the VP. In the first series, the risk was $24 \%(16 / 66)$ at 1 year [74]. These 16 patients suffered 26 new VFs, of which $50 \%$ were in vertebrae adjacent to the VP. Trout et al. retrospectively analyzed the data of 432 patients who had undergone VP and been

Table 4 Risk factors for new VF after percutaneous vertebroplasty or kyphoplasty [47, 68, 76, 78, 79]

Strong risk factors

Patient-level risk factors
Age $(>80$ years $)$
Low bone mineral density $(\mathrm{T}$-score $<-3 \mathrm{DS})$
Low $25 \mathrm{OH}$ vitamin $\mathrm{D}(<20 \mathrm{ng} / \mathrm{mL}$ or $<50 \mathrm{nmol} / \mathrm{L})$
Glucocorticoid therapy
Number of preexisting VF
Vertebra-level risk factors
Intervertebral disc cement leakage
Short time from fracture to procedure
Thoraco-lumbar localization
Number of treated vertebrae

$V F$ vertebral fracture followed up for 1 year [75]. A total of 186 new VFs occurred in 86 patients $(19.9 \%$ ), and in $41 \%$ of these cases, the new fractures were in vertebrae adjacent to the VP. Interestingly, the adjacent VFs occurred earlier than the other fractures (58 versus 127 days, $P<0.001)$. According to the author, this time aspect appeared to indicate that mechanical forces acting between the osteoporotic and cemented vertebrae were to blame, and not the fact that osteoporotic VFs mostly occur in particular spinal locations. However, Diamond et al. compared a VP group with a control group and reported a similar radiological refracture risk of 43 and $44 \%$, respectively [40]. Half of these new VFs were adjacent to the initial VF. In the FREE trial, which compared KP with conventional treatment, between 22 and $27 \%$ of patients suffered a new radiological VF at 3 months, $38 \%$ at 12 months, and between 44 and $48 \%$ at 24 months, with no difference noted between the two groups [53]. This was also the case in VERTOS II, in which there was no difference in the risk of refracture at 1 year between the two groups [76]. The only risk factor for a new VF was the number of preexisting VFs. In the Italian EVEREST cohort, the risk of new clinical VFs in osteoporosis (maximum follow-up 12 months) was $13 \%$, of which $70 \%$ were immediately above or below the vertebra treated by VP [71]. In the randomized study of Blasco et al., 29 new radiological VFs were observed in 17/64 patients treated by VP, whereas there were eight in $8 / 61$ control patients [48]. Of these VFs, 71 and $9 \%$ were clinical in the VP and control groups, respectively. The risk of new radiological VF was 2.78 higher (OR 2.78; $95 \% \mathrm{CI}, 1.02-7.62, P=0.046$ ), and the risk of new clinical VF was 25.67 higher (OR 25.67; $95 \%$ CI, 3.04-216.8, $P=0.029$ ), in the VP group compared with the control group. Intradiscal cement leakage was more frequently observed in patients with new VF (OR 7.17; $95 \%$ CI, 1.69-30.42, $P=0.008)$. 
In an Alabama cohort involving 212 patients who had suffered a VF, 48 underwent VP/KP and 164 received conservative treatment [77]. The adjusted relative risk of suffering a new radiological VF was $6.8(1.7-26.9)$ at 3 months and 2.9 (1.1-7.9) at 12 months for the group treated by VP/KP. In a series of 144 patients who had undergone VP and were followed up for 2 years, the risk of new clinical VF was $27 \%$, of which $56 \%$ adjacent to the vertebra treated [78]. The adjacent VFs occurred within 149 days, and the other VFs within 367 days. Multivariate analysis showed that the risk factors for a new VF were the number of VPs, inhomogeneous cement distribution, and a low Hounsfield unit value on CT. In the randomized controlled study published by Blasco et al., multivariate analysis showed that the risk factors for a new VF following VP were: $25 \mathrm{OH}$ vitamin D level $<20 \mathrm{ng} / \mathrm{mL}$ (RR 15,47, $95 \% \mathrm{CI}, 2.99-79.86$ ), glucocorticoid therapy (RR $3.64,95 \% \mathrm{CI}, 1.61-8.26$ ), and age $>80$ years (RR 3.20 , $95 \% \mathrm{CI}, 1.70-6.03)[48,79]$. The risk of suffering a new radiological VF was modeled in a series of 115 patients having undergone 216 VPs [80]. The probability of being fracturefree at 1 year ranged from $98.3 \%(97.5-100)$ to $17.5 \%(1.17-$ 33.8) depending on the risk factors. Poor prognostic factors were lowered bone mineral density (especially $<-3 \mathrm{SD}$ ), the severity of vertebral deformation, recent fracture, fracture in the thoracolumbar junction, and intradiscal cement leakage. There was a clear link between the volume of intradiscal cement and refracture risk. In fractures adjacent to the vertebra that was treated, mean intradiscal cement volume was $0.45 \mathrm{~mL}$, compared with $0.21 \mathrm{~mL}$ in the group with no new fractures $(P<0.004)$. A systematic review included 24 observational studies published between 2004 and 2012 covering 3 , 789 patients who had undergone 5,464 vertebroplasties [69]. Mean follow-up was 22.8 months. The risk of a new clinical VF was $25.5 \%$. The authors identified three strong risk factors for fracture recurrence (decreased bone mineral density, intradiscal cement leakage, and vertebral height restoration) and six moderate risk factors (old age, decreased BMI, number of existing VFs, number of VPs, cement leakage, and VP of the thoracolumbar junction). There did not appear to be a difference in the risk of refracture following either VP or KP [26]. Table 4 summarizes the main risk factors for a new vertebral fracture. Even though everyone recognizes that VF is a strong risk factor for VF recurrence, it can clearly be seen from the latest studies and analyses that VP/KP is an additional risk factor for new VFs. What is more, it would seem that it may be possible to identify patients who are at high- or low risk of recurrence.

\section{Discussion}

VF can be a painful event that has a significant impact on quality of life and that does not always respond to the available antalgic drug therapies. VP and KP are therefore logical solutions in these refractory settings. What is more, the fact that vertebral height can be partially or fully restored with KP provides great hope that the loss of quality of life associated with vertebral height loss can be limited. Although the case series that were initially published were all very encouraging, it must be recognized that the results of the randomized studies have been very mixed. Moreover, randomized studies are rare. When comparing VP with a sham-controlled group, no benefit of VP was observed [35, 36, 45]. A potential effect of local anesthesia on the level of pain may account for this. For others, the volume of cement injected (mean cemented vertebral body fraction) appeared to play a decisive role in obtaining pain relief [81]. In the study by Buchbinder et al., the quantity of cement injected per vertebra was $2.0 \pm 1.2 \mathrm{~mL}$ [35]. In the study by Kallmes et al., it was not mentioned [36]. In a series including 106 patients who had undergone 196 VPs, mean cemented vertebral body fraction was significantly smaller in non-responders than in patients who experienced an analgesic benefit ( 15 versus $21 \%, P=0.002$ ) [81]. The mean volume injected was $3.94 \pm 1.89 \mathrm{~mL}(0.13-10.8 \mathrm{~mL})$, but may vary with vertebral level, severity of the fracture, and gender. And indeed, injecting a bigger volume of PMMA increases the risk of cement leakage, and so it may increase the risk of symptomatic side effects and fracture recurrence [80]. Less pressure is required for injecting the PMMA in KP, and the risks of cement leakage are reduced $[65,66]$. However, comparing VP with KP has not shown any difference in terms of analgesic or functional benefits or risks of refracture [26]. KP's benefit is that it limits vertebral height loss and kyphotic angle, but without any impact on the various functional scores used in the studies, usually with a follow-up period of 12 months. It is true that a potential longer term benefit remains unknown. The only randomized controlled study comparing KP with conservative management showed a considerable analgesic and functional benefit that lasted at least 2 years $[52,53]$. There is unfortunately only this one study, and the control group was not sham-controlled.

It is difficult to compare the studies given the highly diverse enrollment criteria and differing measurement tools used. Moreover, the patient populations included in each of the studies were limited in size. Patient age, number of VFs, degree of the VF, time period between VF and VP/KP, volume of PMMA injected, and injection pressure were all enrollment and procedure parameters that varied from study to study. Although pain evaluation is relatively well-standardized and comparable, the tools for measuring functional status and quality of life are extremely varied, and include everything from instruments specifically for osteoporosis to very general instruments. The EuroQol Group 5-Dimension Self-report Questionnaire, SF-36 mental component standardized, SF-36 physical component standardized, Bartel Index, Oswestry Disability Index, RDQ, modified RDQ, Qualeffo-41, and 
Table 5 Proposal for clinical management of symptomatic osteoporotic vertebral fracture

Day 1 to day 28

1. Confirm the fracture by a lateral radiograph of the thoracolumbar spine (or a CT scan if needed)

2. Give analgesics including nonsteroidal analgesics $+/-$ morphine derivatives

3. If the pain is not controlled, add calcitonine

4. Make an osteoporosis and fracture risk assessment

5. Initiate an anti-osteoporotic treatment (antiresorptive or anabolic) with calcium and vitamin D

6. Reassess regularly the clinical course

Day 21 to day 42

1. In case of disabling pain, perform a MRI

2. Evaluate the indication for VP or KP

European Vertebral Osteoporosis Study questionnaire were used to assess the functional improvement and quality of life of patients. In spite of the limited clinical comparisons and scepticism raised by this literature review, a recent metaanalysis has shown greater pain relief, functional recovery, and health-related quality of life with VP or KP compared with controls [82]. VP or KP better results were significant at both the early ( $<3$ months) and late time points ( 6 to 12 months), and the risk of new VF was not statistically different between the groups. One study has a large effect on these results [47]. Of the eight existing randomized controlled studies, that of Blasco et al. showing a significant increase in the risk of new VF after VP was not included, and the study of Rousing et al. was only included for certain analyses [41, 48].

What can we do with a patient with a painful VF in routine clinical practice (Table 5)? The immediate analgesic benefit of $\mathrm{VP} / \mathrm{KP}$ may be an advantage provided that the related risks are low. But what is an acceptable time limit between the onset of pain and performance of the procedure? In VERTOS II for example, the time limit between the onset of pain and the procedure had to be $<6$ weeks. Of the 431 patients who were eligible for randomization, there was a complete disappearance of pain before the performance of VP in 229 (53\%) of them, who were therefore not included [46]. So should we wait at least 6 weeks before suggesting VP/KP? And how long can we wait before performing VP/KP? Does waiting a year lead to a chance of success, as some authors affirm? A delay of a year was seen as a cause of the absence of VP benefit in the studies of Buchlinder and Kallmes [35, 36].

Patients with VF exhibit increased mortality rates. Could performing VP/KP change this? Mc Donald et al. compared 524 patients who had undergone VP with 582 patients (371 asymptomatic, 201 symptomatic) with VF that was treated conservatively [83]. The cohorts were followed up for between 3.7 and 5.4 years. Mortality was the same in the VP group and control group with symptomatic VF. However, mortality was higher in the VP group than in the control group with asymptomatic VF. Estimated survival at 5 years was $56 \%$ for the VP group, $61 \%$ for the symptomatic group that had not undergone VP, and $79 \%$ for the asymptomatic group that had not undergone VP. Another retrospective analysis with a 2-year follow-up did not show any effect on mortality [84]. Edidin et al. analyzed the mortality risk for operated and non-operated VF patients in the Medicare population [85]. The authors identified 858,978 patients with osteoporotic VF between 2005 and 2008, of whom 119,253 underwent KP and 63,693 VP. After 4 years of follow-up, $60.8 \%$ of patients who had undergone VP or KP were alive compared with $50.0 \%$ of patients who had not undergone any intervention (adjusted Hazard Ratio $[\mathrm{aHR}]=0.63, P<0.001$ ). The risk of death was lower in the KP group than it was in the VP group (aHR= $0.77, P<0.001$ ). We are faced with retrospective analyses whose results are contradictory. Despite the various adjustments that were made, the fact remains that the patients to whom we propose a procedure are undoubtedly very different from those to whom we do not propose this procedure.

Cost-effectiveness analyses allow both the advantages and disadvantages of a procedure to be assimilated best, and may be a solution with regard to the benefit of VP/KP. A few studies have been conducted, and all are in favor of VP or KP compared with conventional treatment [86-88]. The results of this study type depend on which parameters are entered into the model. As the benefits of VP/KP are debatable, it is too early for conducting such studies. The results of a recent cost-effectiveness analysis comparing VP with KP were contradictory [89].

Another decisive element is the necessity of rapidly initiating a specific treatment for osteoporosis. Patients suffering from an atraumatic VF have by definition osteoporosis and are at great risk of refracture. Treatment is clearly indicated. In a cohort study involving 9,238 patients who were hospitalized for an osteoporotic VF, undergoing VP/KP increased the probability of receiving an anti-osteoporosis therapy [90]. At 1 month following the VF, $46 \%$ of patients who had undergone VP/ KP were on anti-osteoporosis therapy, compared with $32 \%$ of patients who had not undergone VP/KP. At 6 months, the respective results were 59 and $47 \%$. These results are already better compared to clinical practice and could be further improved in a randomized controlled trial or by clinical pathway. In the FREE study, over the course of 12 months, the number of patients receiving calcium and vitamin $\mathrm{D}$ increased from around 50 to $85 \%$, and the number of those receiving a bisphosphonate increased from around 45 to $75 \%$, with no difference noted between the VP and control groups [52].

\section{Limitations and prospects for the future}

Further randomized controlled studies of good quality are warranted in order to better define the profile of patients 
who may benefit from VP or KP. VERTOS IV will attempt to answer this question and is designed to include patients who are 50 or older, have had a painful VF for less than 6 weeks, and display edema on MRI scans. Patients will be randomized for either VP or a sham intervention [91].

Many questions remain regarding the ideal biomaterials (offering the best biomechanical properties) and best technique (material, injection pressure, or uni- or bilateral approach) to be used. Mixing the cement with a biocompatible liquid may improve the biomechanical properties, thus reducing adjacent VFs. A reduction of $51 \%$ in cement stiffness, which was obtained by adding serum, may reduce the risk of refracture [92]. In a recent randomized controlled trial, no beneficial effect of vertebral body stenting over KP was found among patients with painful osteoporotic VF [93]. In another randomized study, KIVA, a new vertebral augmentation treatment system, yielded better results than KP did for restoring vertebral body wedge deformity, with less cement leakage [94]. In another recent study, a unipedicular approach was recommended for KP rather than a bipedicular one, the benefits obtained being the same [95]. These new techniques require further investigation.

Osteoporotic drug treatments are rarely mentioned in the studies of VP/KP. All patients suffering from a VF must be given calcium, vitamin $\mathrm{D}$, and an antiosteoporotic treatment, ideally a bone anabolic agent, on account of the severity of the underlying osteoporosis. This treatment should be initiated before VP/KP is even considered. What is more, VP/KP has never been compared with optimal osteoporotic drug therapy. Such a clinical study should comprise a randomized design with three arms: (1) VP or KP only, (2) VP or KP with a bone anabolic agent, (3) bone anabolic agent only.

\section{Conclusion}

The efficacy of VP/KP for controlling pain after VF is still a matter of controversy. VP/KP should therefore be reserved for VF patients when a properly managed analgesic treatment has failed, without omitting to initiate osteoporotic therapy. KP differs from VP in that it enables better vertebral height restoration and thus kyphotic angle reduction, but its costs are higher, while its long-term benefit is not known. Recent studies clearly show that both VP and KP increase the risk of new $\mathrm{VFs}$, in particular in the vertebrae adjacent to those treated. These refractures occur within a relatively short time period. Certain risk factors have been identified. It seems therefore appropriate to involve the patients to whom VP/KP is being proposed in the decision-making process. Further randomized controlled studies of good quality are necessary to better identify those patients likely to benefit the most from these procedures.

Conflict of interest None.

\section{References}

1. Cooper C, Atkinson EJ, O'Fallon WM, Melton LJ 3rd (1992) Incidence of clinically diagnosed vertebral fractures: a populationbased study in Rochester, Minnesota, 1985-1989. J Bone Miner Res 7:221-227

2. Cummings SR, Black DM, Rubin SM (1989) Lifetime risks of hip, Colles', or vertebral fracture and coronary heart disease among white postmenopausal women. Arch Intern Med 149:2445-2448

3. Melton LJ 3rd, Lane AW, Cooper C (1993) Prevalence and incidence of vertebral deformities. Osteoporos Int 3:113-119

4. The European Prospective Osteoporosis Study (EPOS) group (2002) Incidence of vertebral fracture in Europe: results from the European Prospective Osteoporosis Study (EPOS). J Bone Miner Res 17:716724

5. Delmas PD, van de Langerijt L, Watts NB et al (2005) Underdiagnosis of vertebral fractures is a worldwide problem: the IMPACT study. J Bone Miner Res 20:557-563

6. Cooper C, Melton LJ (1992) Vertebral fractures. BMJ 304:793-794

7. Casez P, Uebelhart B, Gaspoz JM, Ferrari S, Louis-Simonet M, Rizzoli R (2006) Targeted education improves the very low recognition of vertebral fractures and osteoporosis management by general internists. Osteoporos Int 17:965-970

8. Fink HA, Ensrud KE, Nelson DB et al (2003) Disability after clinical fracture in postmenopausal women with low bone density: the fracture intervention trial (FIT). Osteoporos Int 14:69-76

9. Tosteson AN, Gabriel SE, Grove MR et al (2001) Impact of hip and vertebral fractures on quality-adjusted life years. Osteoporos Int 12: 1042-1049

10. Adachi JD, Ioannidis G, Olszynski WP et al (2002) The impact of incident vertebral and non-vertebral fractures on health related quality of life in postmenopausal women. BMC Musculoskelet Disord 3:11

11. Oglesby AK, Minshall ME, Shen W et al (2003) The impact of incident vertebral and non-vertebral fragility fractures on healthrelated quality of life in established postmenopausal osteoporosis: results from the teriparatide randomized, placebo-controlled trial in postmenopausal women. J Rheumatol 30:1579-1583

12. Fechtenbaum J, Cropet C, Kolta S et al (2005) The severity of vertebral fractures and health-related quality of life in osteoporotic postmenopausal women. Osteoporos Int 16:2175-2179

13. Melton LJ 3rd, Atkinson EJ, Cooper C et al (1999) Vertebral fractures predict subsequent fractures. Osteoporos Int 10:214-221

14. Black DM, Arden NK, Palermo L, Pearson J, Cummings SR, for the Study of Osteoporotic Fractures Research Group (1999) Prevalent vertebral deformities predict hip fractures and new vertebral deformities but not wrist fractures. J Bone Miner Res 14:821-828

15. Burger H, van Daele PL, Algra D et al (1994) Vertebral deformities as predictors of nonvertebral fractures. BMJ 309:991-992

16. Siminoski K, Jiang G, Adachi JD et al (2005) Accuracy of height loss during prospective monitoring for detection of incident vertebral fractures. Osteoporos Int 16:403-410

17. Buckens C, de Jong P, Mali W, Verhaar H, van der Graaf, Verkooijen H (2013) Prevalent vertebral fractures on chest CT: higher risk for future hip fracture. J Bone Miner Res. doi:10.1002/jbmr.2028

18. Delmas PD, Genant HK, Crans GG, Stock JL, Wong M, Siris E, Adachi JD (2003) Severity of prevalent vertebral fractures and the 
risk of subsequent vertebral and nonvertebral fractures: results from the MORE trial. Bone 33:522-532

19. Ettinger B, Black DM, Mitlak BH et al (1999) Reduction of vertebral fracture risk in postmenopausal women with osteoporosis treated with raloxifene: results from a 3-year randomized clinical trial. Multiple Outcomes of Raloxifene Evaluation (MORE) Investigators. JAMA 282:637-645

20. Genant HK, Halse J, Briney WG et al (2005) The effects of teriparatide on the incidence of back pain in postmenopausal women with osteoporosis. Curr Med Res Opin 21:1027-1034

21. Nevitt MC, Chen P, Dore RK et al (2006) Reduced risk of back pain following teriparatide treatment: a meta-analysis. Osteoporos Int 17: 273-280

22. Rajzbaum G, Grados F, Evans D, Liu-Leage S, Petto H, AugendreFerrante B (2013) Treatment persistence and changes in fracture risk, back pain, and quality of life amongst patients treated with teriparatide in routine clinical care in France: Results from the European Forsteo Observational Study. Joint Bone Spine. doi:10. 1016/j.jbspin.2013.05.001

23. Knopp JA, Diner BM, Blitz M et al (2005) Calcitonin for treating acute pain of osteoporotic vertebral compression fractures: a systematic review of randomized, controlled trials. Osteoporos Int 16:12811290

24. Boonen S, Wahl DA, Nauroy et al (2011) Balloon kyphoplasty and vertebroplasty in the management of vertebral compression fractures. Osteoporos Int 22:2915-2934

25. McGirt MJ, Parker SL, Wolinsky JP, Witham TF, Bydon A, Gokaslan ZL (2019) Vertebroplasty and kyphoplasty for the treatment of vertebral compression fractures: an evidenced-based review of the literature. Spine J 9:501-508

26. Xing D, Ma JX, Ma XL et al (2013) A meta-analysis of balloon kyphoplasty compared to percutaneous vertebroplasty for treating osteoporotic vertebral compression fractures. J Clin Neurosci 20: 795-803

27. Galibert P, Deramond H, Rosat P, Le Gars D (1987) Preliminary note on the treatment of vertebral angioma by percutaneous acrylic vertébroplastie. Neurochirurgie 33:166-168

28. Deramond H, Depriester C, Galibert P, Le Gars D (1998) Percutaneous vertebroplasty with polymethylmethacrylate. Technique, indications, and results. Radiol Clin North Am 36:533-546

29. Weisskopf M, Ohnsorge JA, Niethard FU (2008) Intravertebral pressure during vertebroplasty and balloon kyphoplasty: an in vitro study. Spine 33:178-182

30. Kaufmann TJ, Jensen ME, Schweickert PA, Marx WF, Kallmes DF (2001) Age of fracture and clinical outcomes of percutaneous vertebroplasty. AJNR Am J Neuroradiol 22:1860-1863

31. Nieuwenhuijse MJ, van Erkel AR, Dijkstra PD (2012) Percutaneous vertebroplasty for subacute and chronic painful osteoporotic vertebral compression fractures can safely be undertaken in the first year after the onset of symptoms. J Bone Joint Surg Br 94:815-820

32. Lieberman IH, Dudeney S, Reinhardt MK, Bell G (2001) Initial outcome and efficacy of "kyphoplasty" in the treatment of painful osteoporotic vertebral compression fractures. Spine 26:1631-1638

33. Denaro V, Longo UG, Maffulli N, Denaro L (2009) Vertebroplasty and kyphoplasty. Clin Cases Miner Bone Metab 6:125-130

34. Long SS, Morrison WB, Parker S (2012) Vertebroplasty and kyphoplasty in the United States: provider distribution and guidance method, 2001-2010. AJR 199:1358-1364

35. Buchbinder R, Osborne RH, Ebeling PR et al (2009) A randomized trial of vertebroplasty for painful osteoporotic vertebral fractures. $\mathrm{N}$ Engl J Med 361:557-568

36. Kallmes DF, Comstock BA, Heagerty PJ et al (2009) A randomized trial of vertebroplasty for osteoporotic spinal fractures. N Eng J Med 361:569-579

37. Voormolen MH, Mali WP, Lohle PN et al (2007) Percutaneous vertébroplastie compared with optimal pain medication treatment: short-term clinical outcome of patients with subacute or chronic painful osteoporotic vertebral compression fractures. The VERTOS study. AJNR Am J Neuroradiol 28:555-560

38. Diamond TH, Champion B, Clark WA (2003) Management of acute osteoporotic vertebral fractures: a nonrandomized trial comparing percutaneous vertebroplasty with conservative therapy. Am J Med 114:257-265

39. Alvarez L, Alcaraz M, Perez-Higueras A et al (2006) Percutaneous vertebroplasty: functional improvement in patients with osteoporotic compression fractures. Spine 31:1113-1118

40. Diamond TH, Bryant C, Browne L, Clark WA (2006) Clinical outcomes after acute osteoporotic vertebral fractures: a 2-year nonrandomised trial comparing percutaneous vertebroplasty with conservative therapy. Med J Aust 184:113-117

41. Rousing R, Andersen MO, Jespersen SM, Thomsen K, Lauritsen JM (2009) Percutaneous vertebroplasty compared to conservative treatment in patients with painful acute or subacute osteoporotic vertebral fractures: three-month follow-up in a clinical randomized study. Spine 34:1349-1354

42. Rousing R, Hansen KL, Andersen MO, Jespersen SM, Thomsen K, Lauritsen JM (2010) Twelve months follow-up in 49 patients with acute/semiacute osteoporotic vertebral fractures treated conservatively or with percutaneous vertébroplastie: a clinical randomized trial. Spine 35:478-482

43. Bono CM, Heggeness M, Mick C, Resnick D, Watters WC 3rd (2010) North American Spine Society: newly released vertebroplasty randomized controlled trials: a tale of two trials. Spine J 10:238-240

44. Clark WA, Diamond TH, McNeil HP, Gonski PN, Schlaphoff GP, Rouse JC (2010) Vertebroplasty for painful acute osteoporotic vertebral fractures: recent Medical Journal of Australia editorial is not relevant to the patient group that we treat with vertebroplasty. Med J Aust 192:334-337

45. Staples MP, Kallmes DF, Comstock BA et al (2011) Effectiveness of vertebroplasty using individual patient data from two randomised placebo controlled trials: meta-analysis. BMJ 343:d3952. doi:10. 1136/bmj.d3952

46. Klazen CA, Lohle PN, de Vries J et al (2010) Vertebroplasty versus conservative treatment in acute osteoporotic vertebral compression fractures (Vertos II): an open-label randomised trial. Lancet 376:1085-1092

47. Farrokhi MR, Alibai E, Maghami Z (2011) Randomized controlled trial of percutaneous vertebroplasty versus optimal medical management for the relief of pain and disability in acute osteoporotic vertebral compression fractures. J Neurosurg Spine 14:561-569

48. Blasco J, Martinez-Ferrer A, Macho J et al (2012) Effect of vertebroplasty on pain relief, quality of life, and the incidence of new vertebral fractures: a 12-month randomized follow-up, controlled trial. J Bone Miner Res 27:1159-1166

49. Bouza C, Lopez T, Magro A, Navalpotro L, Amate JM (2006) Efficacy and safety of balloon kyphoplasty in the treatment of vertebral compression fractures: a systematic review. Eur Spine J 15: 1050-1067

50. Grafe IA, Da Fonseca K, Hillmeier J et al (2005) Reduction of pain and fracture incidence after kyphoplasty: 1-year outcomes of a prospective controlled trial of patients with primary osteoporosis. Osteoporos Int 16:2005-2012

51. Kasperk C, Hillmeier J, Nöldge G et al (2005) Treatment of painful vertebral fractures by kyphoplasty in patients with primary osteoporosis: a prospective nonrandomized controlled study. J Bone Miner Res 20:604-612

52. Wardlaw D, Cummings SR, Van Meirhaeghe J et al (2009) Efficacy and safety of balloon kyphoplasty compared with non-surgical care for vertebral compression fracture (FREE): a randomised controlled trial. Lancet 373:1016-1024

53. Boonen S, Van Meirhaeghe J, Bastian L et al (2011) Balloon kyphoplasty for the treatment of acute vertebral compression 
fractures: 2-year results from a randomized trial. J Bone Miner Res 26:1627-1637

54. Lee HM, Park SY, Lee SH, Suh SW, Hong JY (2012) Comparative analysis of clinical outcomes in patients with osteoporotic vertebral compression fractures (OVCFs): conservative treatment versus balloon kyphoplasty. Spine J 12:998-1005

55. Liu JT, Liao WJ, Tan WC et al (2010) Balloon kyphoplasty versus vertebroplasty for treatment of osteoporotic vertebral compression fracture: a prospective, comparative, and randomized clinical study. Osteoporos Int 21:359-364

56. Folman Y, Shabat S (2011) A comparison of two new technologies for percutaneous vertebral augmentation: confidence vertebroplasty vs. sky kyphoplasty. Israel Med Assoc J 13:394-397

57. Kumar K, Nguyen R, Bishop S (2010) A comparative analysis of the results of vertebroplasty and kyphoplasty in osteoporotic vertebral compression fractures. Neurosurgery 67:ons171-ons188

58. Movrin I, Vengust R, Komadina R (2010) Adjacent vertebral fractures after percutaneous vertebral augmentation of osteoporotic vertebral compression fracture: a comparison of balloon kyphoplasty and vertebroplasty. Arch Orthop Trauma Surg 130:1157-1166

59. Rollinghoff M, Siewe J, Zarghooni K et al (2009) Effectiveness, security and height restoration on fresh compression fractures - a comparative prospective study of vertebroplasty and kyphoplasty. Minim Invasive Neurosurg 52:233-237

60. Schofer MD, Efe T, Timmesfeld N, Kortmann HR, Quante M (2009) Comparison of kyphoplasty and vertebroplasty in the treatment of fresh vertebral compression fractures. Arch Orthop Trauma Surg 129: 1391-1399

61. Zhou JL, Liu SQ, Ming JH, Peng H, Qiu B (2008) Comparison of therapeutic effect between percutaneous vertebroplasty and kyphoplasty on vertebral compression fracture. Chin J Traumatol 11:42-44

62. Grohs JG, Matzner M, Trieb K, Krepler P (2005) Minimal invasive stabilization of osteoporotic vertebral fractures: a prospective nonrandomized comparison of vertebroplasty and balloon kyphoplasty. J Spinal Disord Tech 18:238-242

63. Lovi A, Teli M, Ortolina A, Costa F, Fornari M, Brayda-Bruno M (2009) Vertebroplasty and kyphoplasty: complementary techniques for the treatment of painful osteoporotic vertebral compression fractures. A prospective non-randomised study on 154 patients. Eur Spine J 18(Suppl 1):95-101

64. Santiago FR, Abela AP, Alvarez LG, Osuna RM, García Mdel M (2010) Pain and functional outcome after vertebroplasty and kyphoplasty. A comparative study. Eur J Radiol 75:108-113

65. Phillips F, Todd W, Lieberman I, Campbell-Hupp M (2002) An in vivo comparison of the potential for extravertebral cement leak after vertebroplasty and kyphoplasty. Spine 27:2173-2178

66. Hulme PA, Krebs J, Ferguson SJ, Berleman U (2006) Vertebroplasty and kyphoplasty: a systematic review of 69 clinical studies. Spine 31: 1983-2001

67. Hadjipavlou AG, Tzermiadianos MN, Katonis PG, Szpalski M (2005) Percutaneous vertebroplasty and balloon kyphoplasty for the treatment of osteoporotic vertebral compression fractures and osteolytic tumours. J Bone Joint Surg Br 87:1595-1604

68. Lee MJ, Dumonski M, Cahill P, Stanley T, Park D, Singh K (2009) Percutaneous treatment of vertebral compression fractures: a metaanalysis of complications. Spine 34:1228-1232

69. Ma X, Xing D, Ma J, et al. (2013) Risk factors for new vertebral compression fractures after percutaneous vertebroplasty: qualitative evidence synthesized from a systematic review. Spine. doi: 10.1097/ BRS.0b013e31828cf15b

70. Venmans A, Klazen CA, Lohle PN et al (2010) Percutaneous vertebroplasty and pulmonary cement embolism: results from VERTOS II. Am J Neuroradiol 31:1451-1453

71. Anselmetti GC, Marcia S, Saba L et al (2012) Percutaneous vertebroplasty: multi-centric results from EVEREST experience in large cohort of patients. Eur J Radiol 81:4083-4086
72. Uppin AA, Hirsch JA, Centenera LV, Pfiefer BA, Pazianos AG, Choi IS (2003) Occurrence of new vertebral body fracture after percutaneous vertebroplasty in patients with osteoporosis. Radiology 226: 119-124

73. Fribourg D, Tang C, Sra P, Delamarter R, Bae H (2004) Incidence of subsequent vertebral fracture after kyphoplasty. Spine 29:2270-2276

74. Voormolen MH, Lohle PN, Juttmann JR, van der Graaf Y, Fransen H, Lampmann LE (2006) The risk of new osteoporotic vertebral compression fractures in the year after percutaneous vertebroplasty. $\mathrm{J}$ Vasc Interv Radiol 17:71-76

75. Trout AT, Kallmes DF, Kaufmann TJ (2006) New fractures after vertebroplasty: adjacent fractures occur significantly sooner. AJNR Am J Neuroradiol 27:217-223

76. Klazen CA, Venmans A, de Vries J et al (2010) Percutaneous vertebroplasty is not a risk factor for new osteoporotic compression fractures: results from VERTOS II. Am J Neuroradiol 31:1447-1450

77. Mudano AS, Bian J, Cope JU et al (2009) Vertebroplasty and kyphoplasty are associated with an increased risk of secondary vertebral compression fractures: a population-based cohort study. Osteoporos Int 20:819-826

78. Liu WG, He SC, Deng G et al (2012) Risk factors for new vertebral fractures after percutaneous vertebroplasty in patients with osteoporosis: a prospective study. J Vasc Interv Radiol 23:1143-1149

79. Martinez-Ferrer A, Blasco J, Carrasco JL et al (2013) Risk factors for the development of vertebral fractures after percutaneous vertebroplasty. J Bone Miner Res 28:1821-1829

80. Nieuwenhuijse MJ, Putter H, van Erkel AR, Dijkstra PD (2013) New vertebral fractures after percutaneous vertebroplasty for painful osteoporotic vertebral compression fractures: a clustered analysis and the relevance of intradiskal cement leakage. Radiology 266:862-870

81. Nieuwenhuijse MJ, Bollen L, van Erkel AR, Dijkstra PD (2012) Optimal intravertebral cement volume in percutaneous vertebroplasty for painful osteoporotic vertebral compression fractures. Spine 37: $1747-1755$

82. Anderson PA, Froyshteter AB, Tontz WL Jr (2013) Meta-analysis of vertebral augmentation compared with conservative treatment for osteoporotic spinal fractures. J Bone Miner Res 28:372-382

83. McDonald RJ, Achenbach SJ, Atkinson EJ et al (2011) Mortality in the vertebroplasty population. Am J Neuroradiol 32:1818-1823

84. Levy H, Seydafkan S, Rice JD, Easley KA, Tangpricha V (2012) Comparative efficacy of vertebroplasty, kyphoplasty, and medical therapy for vertebral fractures on survival and prevention of recurrent fractures. Endocr Pract 18:499-507

85. Edidin AA, Ong KL, Lau E, Kurtz SM (2011) Mortality risk for operated and nonoperated vertebral fracture patients in the Medicare population. J Bone Miner Res 26:1617-1626

86. Masala S, Ciarrapico AM, Konda D, Vinicola V, Mammucari M, Simonetti G (2008) Cost-effectiveness of percutaneous vertebroplasty in osteoporotic vertebral fractures. Eur Spine J 17: $1242-1250$

87. Ström O, Leonard C, Marsh D, Cooper C (2010) Cost-effectiveness of balloon kyphoplasty in patients with symptomatic vertebral compression fractures in a UK setting. Osteoporos Int 21:1599-1608

88. Kasperk C, Grafe IA, Schmitt S et al (2010) Three-year outcomes after kyphoplasty in patients with osteoporosis with painful vertebral fractures. J Vasc Interv Radiol 21:701-709

89. Ong KL, Lau E, Kemner JE, Kurtz SM (2013) Two-year cost comparison of vertebroplasty and kyphoplasty for the treatment of vertebral compression fractures: are initial surgical costs misleading? Osteoporos Int 24:1437-1445

90. Tsai YW, Hsiao FY, Wen YW et al (2013) Clinical outcomes of vertebroplasty or kyphoplasty for patients with vertebral compression fractures: a nationwide cohort study. J Am Med Dir Assoc 14:41-47

91. Firanescu C, Lohle PN, de Vries J et al (2011) A randomised sham controlled trial of vertebroplasty for painful acute osteoporotic vertebral fractures (VERTOS IV). Trials 12:93 
92. Kolb JP, Kueny RA, Püschel K et al (2013) Does the cement stiffness affect fatigue fracture strength of vertebrae after cement augmentation in osteoporotic patients? Eur Spine J 22:1650-1656

93. Werner CM, Osterhoff G, Schlickeiser J et al (2013) Vertebral body stenting versus kyphoplasty for the treatment of osteoporotic vertebral compression fractures: a randomized trial. J Bone Joint Surg Am 95:577-584
94. Korovessis P, Vardakastanis K, Repantis T, Vitsas V (2013) Balloon kyphoplasty versus KIVA vertebral augmentation - comparison of 2 techniques for osteoporotic vertebral body fractures: a prospective randomized study. Spine 38:292-299

95. Rebolledo BJ, Gladnick BP, Unnanuntana A, Nguyen JT, Kepler CK, Lane JM (2013) Comparison of unipedicular and bipedicular balloon kyphoplasty for the treatment of osteoporotic vertebral compression fractures: a prospective randomised study. Bone Joint J 95:401-406 